\title{
Effect of Methylxanthines on Diaphragmatic Fatigue in the Piglet
}

\author{
DENNIS E. MAYOCK, THOMAS A. STANDAERT, AND DAVID E. WOODRUM \\ University of Washington School of Medicine, Department of Pediatrics, Division of Neonatal and Respiratory \\ Diseases, Seattle, Washington 98195
}

\begin{abstract}
Studies in adult animal and human subjects have suggested that the methylxanthine drugs can delay the onset or attenuate the severity of diaphragmatic fatigue. We have investigated the effect of aminophylline and caffeine on the pressure-generating capacity of the fatigued diaphragm in 1-mo-old piglets. Measurements of ventilation, transdiaphragmatic pressure, blood gases and $\mathrm{pH}$, diaphragmatic electromyogram, diaphragmatic pressurefrequency curve (PdiFC), diaphragmatic blood flow, and end-expiratory lung volume were obtained at baseline, after 90 min of inspiratory resistive loaded breathing (IRL), and again 30 min after methylxanthine infusion while still on IRL. IRL resulted in a significant decrease in minute ventilation secondary to a fall in tidal volume. Spontaneously generated transdiaphragmatic pressure increased 7-fold from baseline. EMG activity increased to both segments of the diaphragm. Abdominal expiratory muscle activity was noted after the onset of IRL and was accompanied by a fall in end-expiratory lung volume. The PdiFC was significantly decreased from baseline after $90 \mathrm{~min}$ of IRL, demonstrating diaphragmatic fatigue. Aminophylline did not alter the PdiFC of the diaphragm. Diaphragmatic electromyogram and tidal volume increased. No change in diaphragmatic blood flow was demonstrable after infusion of aminophylline. Serum theophylline levels averaged 117 $\pm 11 \mu \mathrm{mol} / \mathrm{L}(21 \pm 2 \mu \mathrm{g} / \mathrm{mL})$. Caffeine administration did not alter the PdiFC or the diaphragmatic electromyogram during IRL. Blood flow to both segments of the diaphragm decreased after caffeine infusion. Serum caffeine levels averaged $86 \pm 30 \mu \mathrm{mol} / \mathrm{L}(16.6 \pm 5.9 \mu \mathrm{g} / \mathrm{mL})$. We conclude that the methylxanthines, aminophylline and caffeine, do not reverse the loss of pressure generation by the diaphragm that occurs after $90 \mathrm{~min}$ of IRL in the anesthetized piglet. (Pediatr Res 32: 580-584, 1992)
\end{abstract}

\section{Abbreviations}

Pdi, transdiaphragmatic pressure

PdiFC, diaphragmatic pressure frequency curve

IRL, inspiratory resistive loaded breathing

EMG, electromyogram

FRC, functional residual capacity

$\mathrm{PaCO}_{2}$, arterial carbon dioxide tension

Methylxanthine drugs have been shown to increase the force output of the diaphragm in adult humans and animal models

Received March 18, 1992; accepted July 14, 1992.

Correspondence: Dennis E. Mayock, M.D., Division of Neonatal and Respiratory Diseases, Department of Pediatrics, University of Washington, Seattle, WA 98195. No reprints available.

Supported by NIH Program Project Grant HL 39187
(1-7). Improved force output was documented for both fatigued $(1,3,6,7)$ and nonfatigued diaphragmatic muscle $(1,7)$. Some investigators have found little or no improvement in diaphragmatic contractility after methylxanthine therapy (8-12), whereas others have demonstrated that methylxanthines may, in fact, aggravate diaphragmatic fatigue $(13,14)$.

Methylxanthines have recently been proposed as adjunctive therapy in weaning preterm infants from mechanical ventilation (15). Preliminary reports have suggested that methylxanthines may improve diaphragmatic pressure output during the neonatal period $(16,17)$. Lopes et al. (16) found that theophylline increased mouth occlusion pressure for a given diaphragmatic EMG level in preterm human infants. However, only three infants were completely studied, and this preliminary investigation has not been subsequently confirmed. More recently, McGilliard and Farrell (17) presented preliminary evidence that methylxanthines produced a dose-dependent increase in twitch tension in isolated neonatal rat diaphragm. However, the concentration of drug used was high, and it is not clear that the effect would be present at clinically acceptable dosages.

We have previously demonstrated that aminophylline does not change the pressure-generating capacity of the nonfatigued piglet diaphragm during spontaneous breathing (18), nor was there any effect on resting diaphragmatic blood flow (19). The present study was designed to examine the effect of methylxanthines on fatigued diaphragm for several reasons. First, these medications are widely used in neonatal medicine during ventilatory weaning procedures (15) presumably to augment pressure-generating capacity of the weakened or fatigued diaphragm. However, data to support such an approach are lacking. Second, the two medications may differ in their mechanisms of action at the muscle tissue level $(2,20,21)$ and thus may differ in their efficacy. Last, previous investigations suggested that the fatigued muscle may exhibit a greater response to methylxanthines than fresh muscle $(1,3,22)$

\section{MATERIALS AND METHODS}

The study was approved by the University of Washington institutional animal review board. Fifteen piglets (mean postnatal age $30 \pm 2 \mathrm{~d}$ and mean body weight $7.9 \pm 1.2 \mathrm{~kg}$ ) were studied. Only healthy animals with a respiratory rate of $15-30$ breaths/ min and $\mathrm{a}_{\mathrm{PaCO}_{2}}$ equal to or less than $6.7 \mathrm{kPa}$ (50 torr) were accepted for study. The animals were anesthetized with an i.v. combination of chloralose $(30 \mathrm{mg} / \mathrm{kg})$ and urethane $(150 \mathrm{mg} /$ $\mathrm{kg}$ ) and studied in the supine position. Subsequent infusions of anesthetic were used if the piglet developed jaw clonus (usually every 45-60 min), but not within $30 \mathrm{~min}$ of data collection. A tracheostomy was placed and connected to a two-way nonrebreathing valve (model 2384, Hans Rudolph, Inc., Kansas City, $\mathrm{MO}$ ). Inspiratory tidal flow was measured with a pneumotachograph and the signal was integrated (Hewlett-Packard 8815A, Hewlett-Packard, North Hollywood, CA) to give tidal volume. 
All animals breathed $50 \%$ inspired oxygen, balance nitrogen, throughout the study to avoid hypoxemia. A femoral artery catheter was placed to assess blood pressure and heart rate and to obtain samples for blood gas and $\mathrm{pH}$ analysis.

PdiFC were generated by the transvenous phrenic nerve stimulation technique as previously described (23-25). The phrenic nerves were stimulated via bilateral external jugular vein catheter electrodes with supramaximal voltage at $20,30,50$, and $100 \mathrm{~Hz}$ for $2 \mathrm{~s}$. This technique allows for control of central respiratory drive to the diaphragm and excludes the possibility of altered CNS output. Pdi during airway occlusion at end-expiration was measured as gastric pressure minus proximal airway pressure (26). Proximal airway pressure was measured by a P10EZ (Spectramed, Inc., Oxnard, CA) pressure transducer connected to an 18-gauge needle inserted in the tracheostomy tube between the animal and the nonrebreathing valve. A thin-walled latex balloon containing $0.5 \mathrm{~mL}$ of air was connected to a polyethylene catheter ( $1.65 \mathrm{~mm}$ inner diameter) and placed in the stomach to measure gastric pressure with a similar transducer.

The tension-time index of the diaphragm was calculated as the product of Pdi/Pdimax and inspiratory duty cycle $(25,27)$. Endexpiratory lung volume or FRC was measured by the nitrogen washout technique.

Fatigue of the diaphragm was induced by IRL as previously described (25). The resistive load was slowly increased until the animal generated a Pdi during spontaneous breathing that was at least five times that recorded during the baseline period. Previous investigation in our laboratory has demonstrated that the piglet diaphragm can be fatigued after $1 \mathrm{~h}$ of IRL following the same protocol used in the present study (25). Indeed, diaphragmatic fatigue induced by this IRL protocol is progressive (25). The 90-min study point was arbitrarily chosen to provide for further stress and, therefore, more fatigue of the diaphragm. The load was not quantified for each individual animal, but the valve's resistance was measured as 0.024 to $0.041 \mathrm{kPa} / \mathrm{mL} \cdot \mathrm{s}$ $\left(0.24-0.42 \mathrm{~cm} \mathrm{H}{ }_{2} \mathrm{O} / \mathrm{mL} \cdot \mathrm{s}\right)$ at $1-3 \mathrm{~L} / \mathrm{min}$, the peak inspiratory flow rate of these animals.

Core temperature was continuously monitored and maintained between 38.5 and $39.5^{\circ} \mathrm{C}$ with a radiant warmer. A 5 French flow-directed thermodilution catheter (American Edwards Laboratories, Irvine, CA) with a $10-\mathrm{cm}$ proximal port was placed via the right external jugular vein under fluoroscopic guidance into the left branch of the pulmonary artery. Cardiac output determinations were made in triplicate with $2 \mathrm{~mL}$ iced $5 \%$ dextrose using a 9520A Cardiac Output Computer (American Edwards Laboratories).

A preformed plaster cast covering the entire abdomen and the lower third of the chest was applied only during PdiFC generation to ensure a constant abdominal volume and, therefore, diaphragm shortening geometry. The piglets were allowed to breathe unrestricted between stimuli. Chest wall distortion during PdiFC curve generation was assessed by inductance plethysmography (Respitrace, Ambulatory Monitoring, Ardsley, NY). The degree of distortion was quantified in arbitrary units at each study period during phrenic nerve stimulation with end-expiratory airway occlusion. End-expiratory lung volume (FRC) was measured by the nitrogen washout technique to assess, at each study point, the effect of the protocol on lung volume and, thus, diaphragmatic length. The PdiFC was obtained before and again after adjusting lung volume back to the baseline value. Lung volume was adjusted back to the baseline value in each animal to allow for comparison of Pdi generation at each stage in the protocol (28). Lung volume was adjusted to baseline FRC volume by injecting the required volume rapidly (about $1 \mathrm{~s}$ ) into the tracheostomy tube after occlusion just before to phrenic nerve stimulation.

Diaphragmatic EMG signals were obtained from both the costal and crural segments and recorded differentially to ground on FM tape (Honeywell 5600C, Honeywell, Denver, CO). The costal electrodes were two insulated, multistranded steel wires placed approximately $4 \mathrm{~mm}$ apart into the paratendinous part of the right costal diaphragm via a subcostal extraperitoneal incision. After placement, the surgical incision was closed. The crural electrodes were also insulated, multistranded steel wires that were placed percutaneously into the right crura. Only EMG signals free of noise as previously demonstrated (29) were analyzed. The EMG signals were amplified (Grass P511, Grass Medical Instruments, Quincy, MA), full-wave rectified, filtered from 30 to $3000 \mathrm{~Hz}$, and integrated through a 1st-order resistance-capacitance network (time constant $100 \mathrm{~ms}$ ) (Service Associates 414, Service Associates, Encinitas, CA) before recording. Peak integrated EMG from both segments of the diaphragm was determined for each study point.

To address the effects of drug exposure on diaphragmatic blood flow, radiolabeled microspheres were used following the reference sample method as previously described (25). A 4.1 French pediatric pigtail catheter (Cook Inc., Bloomington, IN) was advanced into the left ventricle via the left carotid artery under fluoroscopic guidance for microsphere injection. Location of the catheter tip was confirmed by pressure tracing and at postmortem examination. A second catheter was placed into the left femoral artery for withdrawal of the reference sample using a calibrated withdrawal pump (Harvard Apparatus, Millis, MA). Fifteen- $\mu \mathrm{m}$ microspheres labeled with either ${ }^{46} \mathrm{Sc},{ }^{95} \mathrm{Nb},{ }^{103} \mathrm{Ru},{ }^{113} \mathrm{Sn}$, or ${ }^{141} \mathrm{Ce}$ (DuPont, Wilmington, DE) were used in these experiments. Microspheres were diluted to a total volume of $2 \mathrm{~mL}$ with heparinized $0.9 \%$ saline. Before injection, the microsphere solutions were sonicated for $2 \mathrm{~min}$, then shaken with a vortex mixer for $2 \mathrm{~min}$. The microspheres were injected via the left ventricular catheter over a 30 -s period while a simultaneous arterial reference sample was withdrawn from the aorta at a rate of $4.94 \mathrm{~mL} / \mathrm{min}$ for $2 \mathrm{~min}$, beginning $5 \mathrm{~s}$ before initiation of the injection. At the end of the experiment, the animals were killed with an overdose of sodium pentobarbital. The diaphragm and both kidneys were removed and all fat was excised. The central tendon was removed from the diaphragm and the costal and crural components were separated and weighed. Tissue specimens were counted with a gamma scintillation spectrometer (Minaxi 5000 series, Packard, Laguna Hills, CA). Comparative blood flow to right and left kidneys was used as an index of adequate microsphere mixing within the left ventricle. Only those injections that resulted in a less than $15 \%$ difference between the two kidneys were used in analysis.

Experimental protocol. Each of the following measures was obtained at baseline, after $90 \mathrm{~min}$ of IRL, and $30 \mathrm{~min}$ after methylxanthine infusion (aminophylline $20 \mathrm{mg} / \mathrm{kg}, n=8$; or caffeine $30 \mathrm{mg} / \mathrm{kg}, n=7$; both infused over $10 \mathrm{~min}$ ) while still on IRL: arterial $\mathrm{pH}$ and blood gases, respiratory rate, tidal volume, heart rate, blood pressure, cardiac output, diaphragmatic blood flow, Pdi, FRC, chest wall distortion, PdiFC (with and without volume adjustment as necessary), and EMG signals from the costal and crural segments of the diaphragm. Ventilatory (tidal volume, respiratory rate, and inspiratory time) and hemodynamic parameters (heart rate and blood pressure) and Pdi were the average of a $60-\mathrm{s}$ epoch. Serum theophylline or caffeine levels were obtained $30 \mathrm{~min}$ after completion of the drug infusion.

Statistical analysis. Data are presented as the mean \pm SD unless otherwise noted. Variables were compared before, at 90 min of IRL, and after $30 \mathrm{~min}$ of combined methylxanthine and IRL by analysis of variance corrected for multiple comparisons. For variables identified as significant by analysis of variance, paired two-tailed $t$ tests were used to define which values were different. Statistical significance was defined as $p<0.05$.

\section{RESULTS}

$I R L$. The response to IRL was similar in both groups of animals. Tidal volume and minute ventilation decreased significantly during the 90 min of loaded breathing and $\mathrm{PaCO}_{2}$ increased. There were no changes in respiratory rate, heart rate, 
blood pressure, or cardiac output. Spontaneously generated Pdi increased 7-fold by design (Table 1). Blood flow was significantly augmented to both segments of the diaphragm (Table 2); crural blood flow was augmented to a greater degree than costal blood flow. IRL resulted in an increase in peak integrated EMG to both segments of the diaphragm (Table 3). All animals exhibited active expiratory abdominal muscle contraction by visual observation shortly after IRL was initiated (Fig. 1), and FRC decreased significantly (Table 1). The PdiFC fell by approximately $20 \%$ at all frequencies of stimulation at $90 \mathrm{~min}$ of IRL (Fig. 2).

The time-tension index increased from $0.02 \pm 0.01$ at baseline to $0.17 \pm 0.05$ by $90 \mathrm{~min}$ of IRL $(p<0.0001)$. Chest wall distortion at each stimulation frequency during PdiFC generation as assessed by inductance plethysmography was constant from baseline to $90 \mathrm{~min}$ of IRL.

$I R L+$ aminophylline. Aminophylline at a dose of $20 \mathrm{mg} / \mathrm{kg}$ resulted in serum levels of $117 \pm 11 \mu \mathrm{mol} / \mathrm{L}(21.3 \pm 1.9 \mu \mathrm{g} / \mathrm{mL})$ at $30 \mathrm{~min}$ after infusion. A small but significant increase in tidal volume was seen after aminophylline (Table 1). Respiratory rate did not change. Minute ventilation increased and was no longer significantly decreased from the baseline value. Notably, spontaneously generated Pdi did not increase. No alterations in heart rate, blood pressure, cardiac output, $\mathrm{PaCO}_{2}, \mathrm{FRC}$, or diaphragmatic blood flow were found (Tables 1 and 2). The mean peak integrated EMG of both portions of the diaphragm increased, but only the costal portion was significantly increased over the value at 90 min of IRL (Table 3, Fig. 1).

Chest wall distortion at each stimulation frequency during PdiFC was not different from baseline or $90 \mathrm{~min}$ of IRL. The time-tension index after aminophylline was $0.16 \pm 0.04$ and was not different from 90 min of IRL. After aminophylline infusion, the PdiFC was still depressed below baseline and was not different from $90 \mathrm{~min}$ of IRL (Fig. 2).

$I R L+$ caffeine. Caffeine at a dose of $30 \mathrm{mg} / \mathrm{kg}$ resulted in serum levels of $86 \pm 30 \mu \mathrm{mol} / \mathrm{L}(16.6 \pm 5.9 \mu \mathrm{g} / \mathrm{mL})$ at $30 \mu \mathrm{min}$ after infusion. No significant alterations in minute ventilation, tidal volume, respiratory rate, $\mathrm{PaCO}_{2}$, heart rate, blood pressure, cardiac output, FRC, or Pdi were found (Table 1). Blood flow decreased significantly to both segments of the diaphragm by 30 min after caffeine infusion (Table 2). The mean peak integrated EMG of both portions of the diaphragm was not different from the value at 90 min of IRL (Table 3 ).

Chest wall distortion at each stimulation frequency during PdiFC was not different from baseline or 90 min IRL. The timetension index after caffeine was $0.14 \pm 0.04$ and was not different from 90 min of IRL. After caffeine infusion, the PdiFC was still depressed below baseline and was not different from 90 min of IRL (Fig. 3).

\section{DISCUSSION}

The design of this study was such that the experimental animals were initially subjected to resistive loaded breathing sufficient to cause moderate, but well compensated, fatigue of the diaphragm. The animals were clearly operating in the timetension index range that has previously been reported to be compatible with fatiguing activity (27). The methylxanthines, aminophylline and caffeine, did not reverse the loss of pressuregenerating capacity of the diaphragm secondary to IRL in the anesthetized piglet. The data from this study suggest that the beneficial effects of methylxanthines reported in neonates are not related to improvement in diaphragmatic contractility.

Critique. The accuracy of techniques used in this study to determine the pressure-generating capability of the diaphragm have previously been critiqued $(18,25)$. The PdiFC was used to assess Pdi generation. This technique excludes the effect of altered central drive by controlling phrenic nerve input to the diaphragm (21). It is also important to note that the IRL used to induce diaphragmatic fatigue results in the onset of abdominal expiratory muscle activity $(18,24,25)$. This results in a decrease in end-expiratory lung volume that most likely causes a lengthening in the diaphragm and a presumed improvement in the length-tension status $(30,31)$. The PdiFC unadjusted for the decrease in end-expiratory lung volume would than underestimate the loss of pressure-generating capacity of the diaphragm. Accordingly, the PdiFC was obtained after adjustment of the FRC back to the baseline value by injecting a volume of gas into the tracheostomy tube after occlusion at end expiration before phrenic nerve stimulation. The assumption was made that the added volume, equal to the change in FRC, would be distributed throughout the lung in a similar pattern as during baseline spontaneous breathing and that this maneuver would result in passive shortening of the diaphragm (30), returning it to its original length (28).

Methylxanthines and muscle function. The methylxanthines have been shown to influence muscle function by altering calcium ion flux across cell membranes, including the sarcolemma, sarcoplasmic reticulum, and the t-tubular system $(2,13,32,33)$. Moreover, both caffeine and theophylline raise intracellular pH (34), potentially enhancing sarcoplasmic reticulum calcium ion reuptake and release (35). Such effects are expected to result in an increased calcium ion availability at the level of muscle contractile proteins causing an augmentation of force generation. However, some differences in action of these two methylxanthines have been noted. Esau found that, unlike theophylline (20), caffeine did not hyperpolarize adult hamster diaphragm muscle cells (21). Aubier et al. (2) demonstrated that the improvement in Pdi secondary to aminophylline could be abolished by verapamil, whereas the similar potentiating effect of caffeine was not altered. These studies suggest that theophylline, but not caffeine, acts at the muscle cell membrane level.

The available literature examining the effects of methylxanthines on diaphragmatic contractility is contradictory. These medications have been shown to augment diaphragmatic con-

Table 1. Ventilatory and hemodynamic measurements*

\begin{tabular}{lcccccccc}
\hline & $\mathrm{Ve}$ & $\mathrm{Vt}$ & $\mathrm{PaCO}_{2}$ & $\mathrm{HR}$ & $\mathrm{BP}$ & $\mathrm{CO}$ & $\mathrm{FRC}$ & $\mathrm{Pdi}$ \\
\hline $\begin{array}{l}\text { Aminophylline-treated animals } \\
\quad(n=8)\end{array}$ & & & & & & & & \\
Baseline & $161 \pm 53$ & $8.5 \pm 1.9$ & $6.3 \pm 0.5$ & $153 \pm 21$ & $13.6 \pm 0.9$ & $201 \pm 44$ & $15 \pm 2$ & $0.5 \pm 0.2$ \\
$90^{\prime}$ IRL & $116 \pm 24 \dagger$ & $5.1 \pm 1.1 \dagger$ & $9.5 \pm 1.1 \dagger$ & $208 \pm 32$ & $14.5 \pm 2.4$ & $198 \pm 56$ & $12 \pm 4 \dagger$ & $3.5 \pm 1.2 \dagger$ \\
Aminophylline & $128 \pm 13$ & $5.6 \pm 1.0 \dagger \ddagger$ & $9.7 \pm 1.2 \dagger$ & $247 \pm 20$ & $13.3 \pm 0.9$ & $199 \pm 44$ & $12 \pm 4 \dagger$ & $3.6 \pm 1.1 \dagger$ \\
Caffeine-treated animals $(n=7)$ & & & & & & & & \\
$\quad$ Baseline & $168 \pm 63$ & $8.5 \pm 0.9$ & $6.4 \pm 0.5$ & $143 \pm 39$ & $13.1 \pm 1.2$ & $186 \pm 40$ & $14 \pm 3$ & $0.4 \pm 0.1$ \\
90' IRL & $100 \pm 19 \dagger$ & $4.9 \pm 0.5 \dagger$ & $8.9 \pm 0.4 \dagger$ & $178 \pm 37$ & $13.3 \pm 2.0$ & $203 \pm 51$ & $10 \pm 3 \dagger$ & $2.9 \pm 0.3 \dagger$ \\
Caffeine & $101 \pm 34 \dagger$ & $5.0 \pm 0.8 \dagger$ & $10.1 \pm 1.6 \dagger$ & $168 \pm 41$ & $13.2 \pm 1.7$ & $183 \pm 30$ & $10 \pm 2 \dagger$ & $2.9 \pm 0.4 \dagger$ \\
\hline
\end{tabular}

* 90' IRL, values after 90 min of IRL; aminophylline, values $30 \mathrm{~min}$ after aminophylline infusion during IRL; caffeine, values $30 \mathrm{~min}$ after caffeine infusion during IRL; Ve, minute ventilation in $\mathrm{mL} / \mathrm{kg} / \mathrm{min} ; \mathrm{Vt}$, tidal volume in $\mathrm{mL} / \mathrm{kg} ; \mathrm{PaCO}_{2}$, $\mathrm{Pdi}$, and $\mathrm{BP}$ (mean blood pressure) in $\mathrm{kPa}$ $\left(1 \mathrm{kPa}=7.50 \mathrm{~mm} \mathrm{Hg}=10.2 \mathrm{~cm} \mathrm{H} \mathrm{H}_{2} \mathrm{O}\right) ; \mathrm{FRC}$, end-expiratory lung volume in $\mathrm{mL} / \mathrm{kg} ; \mathrm{HR}$, heart rate in beats $/ \mathrm{min} ; \mathrm{CO}$, cardiac output in $\mathrm{mL} / \mathrm{kg} /$ min. All values are mean $\pm \mathrm{SD}$.

$\dagger p<0.05$ compared to baseline.

$\ddagger p<0.05$ compared to IRL. 
Table 2. Diaphragmatic blood flow*

\begin{tabular}{lcclll}
\hline & \multicolumn{2}{c}{ Aminophylline $(n=8)$} & & \multicolumn{2}{c}{ Caffeine $(n=7)$} \\
\cline { 2 - 3 } \cline { 5 - 6 } & Costal & Crural & & Costal & Crural \\
\hline Baseline & $38 \pm 25$ & $30 \pm 9$ & & $27 \pm 13$ & $30 \pm 10$ \\
$90^{\prime}$ IRL & $70 \pm 37 \dagger$ & $103 \pm 59 \dagger$ & & $56 \pm 13 \dagger$ & $92 \pm 17 \dagger$ \\
Methylxanthine & $66 \pm 29 \dagger$ & $98 \pm 48 \dagger$ & $45 \pm 9 \dagger \dagger$ & $78 \pm 19 \dagger \ddagger$ \\
\hline
\end{tabular}

* 90' IRL, values at 90 min of IRL; methylxanthine, values at $30 \mathrm{~min}$ after aminophylline or caffeine infusion during IRL. Flow is given in $\mathrm{mL} / 100 \mathrm{~g} / \mathrm{min}$. Values are mean $\pm \mathrm{SD}$.

$\dagger p<0.05$ compared to baseline.

$\ddagger p<0.05$ compared to IRL.

Table 3. Peak integrated diaphragmatic electromyographic activity (\% baseline)

\begin{tabular}{lccccc}
\hline & \multicolumn{2}{c}{ Aminophylline $(n=8)$} & & \multicolumn{2}{c}{ Caffeine $(n=7)$} \\
\cline { 2 - 3 } \cline { 5 - 6 } & Costal & Crural & & Costal & Crural \\
\hline Baseline & 100 & 100 & & 100 & 100 \\
$90^{\prime}$ IRL & $512 \pm 212 \dagger$ & $541 \pm 68 \dagger$ & & $269 \pm 70 \dagger$ & $375 \pm 67 \dagger$ \\
Methylxanthine & $653 \pm 240 \dagger \ddagger$ & $633 \pm 87 \dagger$ & $313 \pm 105 \dagger$ & $440 \pm 81 \dagger$ \\
\hline
\end{tabular}

* $90^{\prime}$ IRL, values at $90 \mathrm{~min}$ of IRL; methylxanthine, values at $30 \mathrm{~min}$ after aminophylline or caffeine infusion during IRL. Values are mean \pm SEM

$\dagger p<0.05$ compared to baseline.

$\ddagger p<0.05$ compared to $90 \mathrm{~min}$ IRL.
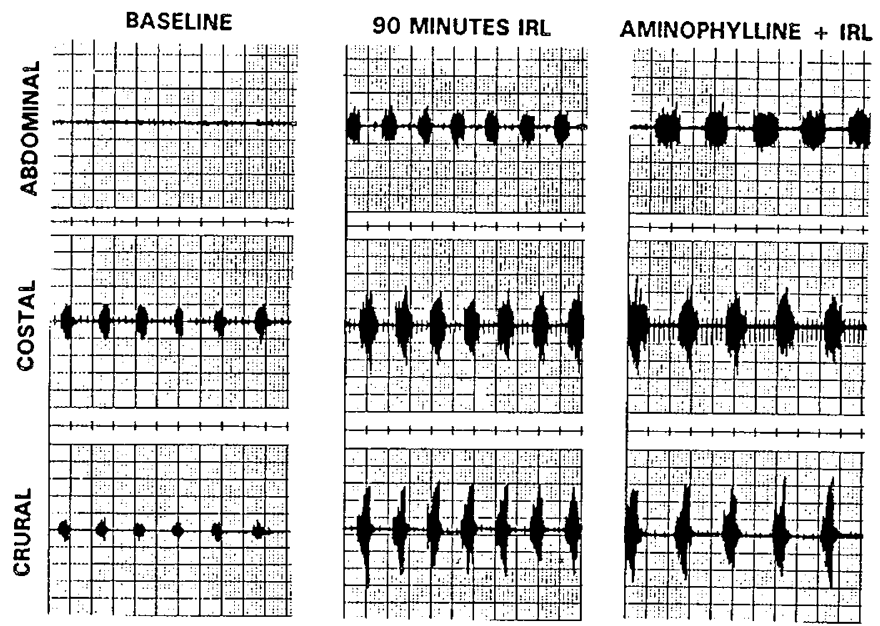

Fig. 1. Representative tracings of raw EMG activity. Upper trace, abdominal EMG activity; middle trace, costal diaphragm EMG activity; lower trace, crural diaphragm EMG activity. Aminophylline $+I R L, 30$ min after aminophylline infusion while still on IRL; all gains held constant during each experimental condition. Note onset of expiratory abdominal muscle activity with IRL.

tractility in adult human and animal models (1-7). In contrast, other investigators could not demonstrate any improvement in diaphragmatic contractility after methylxanthine therapy (8-12). There is minimal information available regarding methylxanthine treatment to augment diaphragmatic contractility in neonates $(16,17)$. Our data suggest that there is no positive inotropic effect of either caffeine or aminophylline on fatigued piglet diaphragm.

The reason for the lack of effect of methylxanthines is unclear, but in all likelihood it is related to immaturity. For example, the diaphragm in a developing animal is functionally different from mature muscle, making the effects of pharmacologic agents on function unpredictable. Subcellular structural differences between immature and mature muscle may explain the lack of effect of methylxanthines on diaphragmatic function during early life. It is known that sarcoplasmic reticulum undergoes consid-

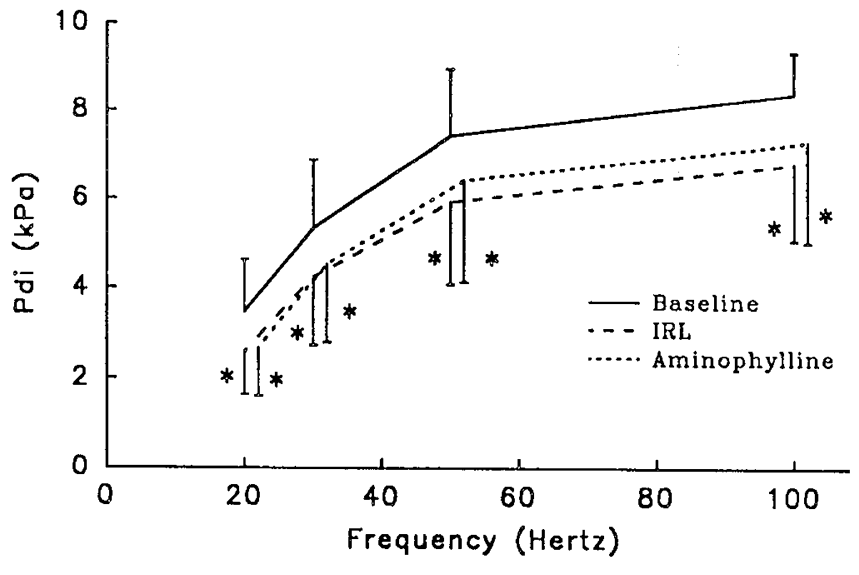

Fig. 2. Aminophylline-treated animals. PdiFC of the diaphragm adjusted for change in end-expiratory lung volume. The PdiFC at $90 \mathrm{~min}$ of IRL is significantly decreased from baseline. At $30 \mathrm{~min}$ after aminophylline infusion, the PdiFC is still significantly decreased from baseline and has not changed from 90 min of IRL. Values are mean $\pm 1 \mathrm{SD} ; n=$ 8. Values at $30 \mathrm{~min}$ after aminophylline are slightly offset for clarity. Frequency of phrenic nerve stimulation is shown in $\mathrm{Hz}$. Pdi is given in $\mathrm{kPa}\left(1 \mathrm{kPa}=10.2 \mathrm{~cm} \mathrm{H}_{2} \mathrm{O}\right) .{ }^{*}, p<0.05$ compared to baseline.

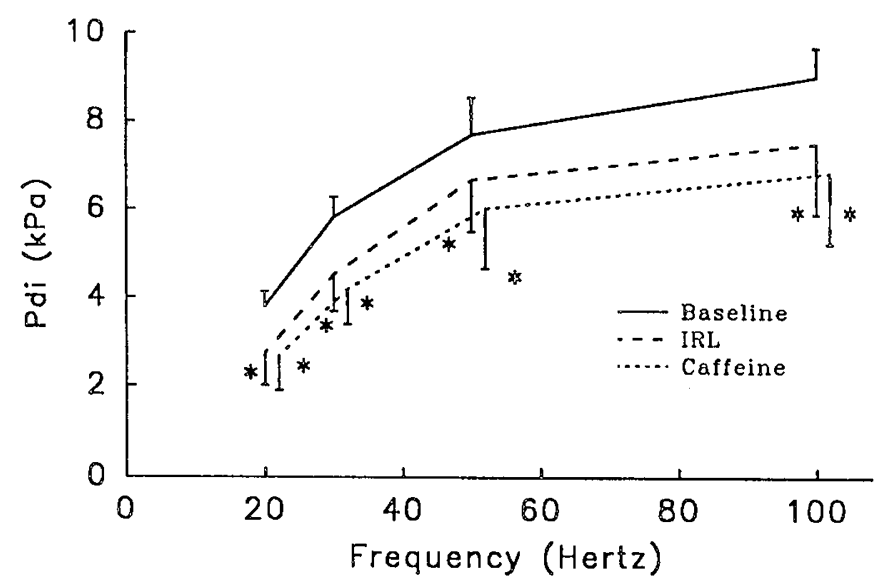

Fig. 3. Caffeine-treated animals. PdiFC of the diaphragm adjusted for change in end-expiratory lung volume. The PdiFC at 90 min of IRL is significantly decreased from baseline. At $30 \mathrm{~min}$ after caffeine infusion, the PdiFC is still significantly decreased from baseline and has not changed from $90 \mathrm{~min}$ of IRL. Values are mean $\pm 1 \mathrm{SD} ; n=7$. Values at $30 \mathrm{~min}$ after caffeine are slightly offset for clarity. Frequency of phrenic nerve stimulation is shown in $\mathrm{Hz}$. Pdi is given in $\mathrm{kPa}(1 \mathrm{kPa}=10.2 \mathrm{~cm}$ $\mathrm{H}_{2} \mathrm{O}$ ). ${ }^{*}, p<0.05$ compared to baseline.

erable structural and functional development during fetal and neonatal life (36). Indeed, it has been suggested that the sarcoplasmic reticulum and t-tubular systems are incompletely developed in the diaphragm of the newborn subhuman primate (37). Thus, improvement in diaphragmatic pressure generation secondary to methylxanthine drugs might be expected to be limited when these important subcellular components of the excitationcontraction process are incompletely developed.

An alternative explanation may be related to the design of the current study that focused on diaphragmatic response to clinically relevant doses of methylxanthines. Sigrist et al. (4) found a dose-related improvement in diaphragmatic contractility after aminophylline administration in the anesthetized adult dog. In contrast to the present study, a measurable effect was present at $20 \mathrm{mg} / \mathrm{kg}$. However, the peak effect was demonstrated at $80 \mathrm{mg} /$ $\mathrm{kg}$, a dose several times greater than used clinically in adult humans. Similar dose-response effects have been demonstrated by other investigators $(9,38)$. It might be speculated that a significant methylxanthine effect on diaphragmatic contractility 
might have been seen at higher doses in the current study, particularly if there are maturationally related functional differences in those factors that are important determinants of intracellular calcium flux. Indeed, a dose-response effect has been reported in preliminary form for the newborn rat diaphragm (17).

The differential effects of caffeine and aminophylline on diaphragmatic EMG and diaphragmatic blood flow of the animals in the current study were not expected. Aminophylline has previously been reported to increase central respiratory drive (39, $40)$. The changes noted in tidal volume and costal diaphragmatic EMG in the present study are in agreement with this mechanism. However, caffeine had no effect. Notably, the changes were small and did not result in improvement in minute ventilation, Pdi, or $\mathrm{PaCO}_{2}$. The reason for the lack of effect of caffeine on ventilation is unclear. It is important to note that the lack of effect of caffeine on ventilation, if supported by additional data, would have major implications for the use of caffeine in the treatment of apnea in neonates.

Caffeine administration also resulted in decreased blood flow to both segments of the diaphragm during IRL, whereas aminophylline was without such effect. The caffeine-induced changes in blood flow are the opposite of those reported in adult humans (41). We do not have an explanation for these results. The small number of animals studied and the large variation between animals may account for the results. However, if such findings are confirmed, the use of caffeine in patients with respiratory distress might be expected to result in further compromise of the integrity of an already fatigued muscle.

Data from the current work suggest that methylxanthines do not improve diaphragmatic contractility in the fatigued piglet diaphragm. We speculate that the reported beneficial effects of methylxanthines in human infants for the treatment of apnea and as adjunctive therapy during weaning from mechanical ventilation appear to be derived from their ability to enhance central respiratory drive rather than a direct effect on diaphragmatic muscle contractility.

\section{REFERENCES}

1. Aubier M, De Troyer A, Sampson M, Macklem PT, Roussos C 1981 Aminophylline improves diaphragmatic contractility. N Engl J Med 305:249-252

2. Aubier M, Murciano D, Viires N, Lecocguic Y, Pariente R 1983 Diaphragmatic contractility enhanced by aminophylline: role of extracellular calcium. J Appl Physiol 54:460-464

3. Murciano D, Aubier M, Lecocguic Y, Pariente R 1984 Effects of theophylline on diaphragmatic strength and fatigue in patients with chronic obstructive pulmonary disease. N Engl J Med 311:349-353

4. Sigrist S, Thomas D, Howell S, Roussos C 1982 The effect of aminophylline on inspiratory muscle contractility. Am Rev Respir Dis 126:46-50

5. Supinski GS, Deal EC, Kelsen SG 1984 The effects of caffeine and theophylline on diaphragm contractility. Am Rev Respir Dis 130:429-433

6. Viires N, Aubier M, Murciano D, Fleury B, Talamo C, Pariente R 1984 Effects of aminophylline on diaphragmatic fatigue during acute respiratory failure. Am Rev Respir Dis 129:396-402

7. Wittmann TA, Kelsen SG 1982 The effect of caffeine on diaphragmatic muscle force in normal hamsters. Am Rev Respir Dis 126:499-504

8. Belman MJ, Sieck GC, Mazar A 1985 Aminophylline and its influence on ventilatory endurance in humans. Am Rev Respir Dis 131:226-229

9. Derom E, Janssens S, De Bock V, Decramer M 1990 Theophylline minimally alters contractile properties of canine diaphragm in vitro. J Appl Physiol 69:1390-1396

10. Levy RD, Nava S, Gibbons L, Bellemare F 1990 Aminophylline and human diaphragm strength in vivo. J Appl Physiol 68:2591-2596

11. Reid MB, Miller MJ 1989 Theophylline does not increase maximal tetanic force or diaphragm endurance in vitro. J Appl Physiol 67:1655-1661
12. Foxworth JW, Reisz GR, Knudson SM, Cuddy PG, Pyszczynski DR, Emory CE 1988 Theophylline and diaphragmatic contractility. Am Rev Respir Dis 138:1532-1534

13. Esau SA 1988 Slowing of relaxation in the fatiguing hamster diaphragm is enhanced by theophylline. J Appl Physiol 65:1307-1313

14. Esau SA 1989 Theophylline enhances fatigue in hamster diaphragm muscle studied in an hypoxic, hypercapnic environment. Am Rev Respir Dis 139:162A(abstr)

15. Durand DJ, Goodman A, Ray P, Ballard RA, Clyman RI 1987 Theophylline treatment in the extubation of infants weighing less than 1,250 grams: a controlled trial. Pediatrics 80:684-688

16. Lopes JM, LeSouef PN, Bryan H, Bryan AC 1982 The effects of theophylline on diaphragmatic fatigue in the newborn. Pediatr Res 16:355A(abstr)

17. McGilliard KL, Farrell LC 1988 Effects of xanthine and adenoside analogs on contractility of the newborn rat diaphragm. Physiologist 31:A7(abstr)

18. Mayock DE, Standaert TA, Watchko JF, Woodrum DE 1990 Effect of aminophylline on diaphragmatic contractility in the piglet. Pediatr Res 28:196198

19. Mayock DE, Twiggs GA, Standaert TA, Watchko JF, Woodrum DE 1989 The effect of aminophylline on diaphragm blood flow in the piglet. Pediatr Res 26:196-199

20. Esau S 1986 Effect of theophylline on membrane potential and contractile force in hamster diaphragm muscle in vitro. $\mathrm{J}$ Clin Invest 77:638-640

21. Esau SA 1988 Differing effect of caffeine and theophylline on resting membrane potential in hamster diaphragm in vitro. Am Rev Respir Dis 137:385A(abstr)

22. Supinski GS, Arnold JS, Kelsen SG 1988 Effect of theophylline on the velocity of diaphragmatic muscle shortening. J Appl Physiol 65:1410-1415

23. Watchko JF, Mayock DE, Standaert TA, Woodrum DE 1986 Diaphragmatic pressures in piglets: direct versus transvenous phrenic nerve stimulation. Pediatr Pulmonol 2:198-201

24. Mayock DE, Badura RJ, Watchko JF, Standaert TA, Woodrum DE 1987 Response to resistive loading in the newborn piglet. Pediatr Res 21:121-125

25. Mayock DE, Standaert TA, Murphy TD, Woodrum DE 1991 Diaphragmatic force and substrate response to inspiratory resistive loaded breathing in the piglet. J Appl Physiol 70:70-76

26. Mayock DE, Watchko JF, Standaert TA, Woodrum DE 1990 Estimation of intrapleural pressure in the newborn. Pediatr Pulmonol 9:30-33

27. Bellemare F, Grassino A 1982 Effect of pressure and timing of contraction on human diaphragm fatigue. J Appl Physiol 53:1190-1195

28. Hubmayr RD, Sprung J, Nelson S 1990 Determinants of transdiaphragmatic pressure in dogs. J Appl Physiol 69:2050-2056

29. Watchko JF, LaFramboise WA, Mayock DE, Standaert TA, Woodrum DE 1987 Spectral analysis of diaphragmatic EMG during the neonatal biphasic hypoxic ventilatory response. Pediatr Res 21:238-241

30. Watchko JF, Standaert TA, Woodrum DE 1987 Diaphragmatic function during hypercapnia: neonatal and developmental aspects. J Appl Physiol 62:768-775

31. Grassino A, Goldman MD, Mead J, Sears TA 1978 Mechanics of the human diaphragm during voluntary contraction: statics. J Appl Physiol 44:829-839

32. Varagic VM, Kentera D 1978 Interactions of calcium, dibutyryl cyclic AMP, isoprenaline and aminophylline on the isometric contraction of the isolated hemidiaphragm of the rat. Naunyn Schmiedebergs Arch Pharmacol 303:4753

33. Weber A 1968 The mechanism of the action of caffeine on sarcoplasmic reticulum. J Gen Physiol 52:760-772

34. Connett $\mathrm{RJ} 1978$ Association of increased $\mathrm{Ph}_{\mathrm{i}}$ with calcium ion release in skeletal muscle. Am J Physiol 234:C110-C114

35. Edwards RHT, Hill DK, Jones DA 1975 Metabolic changes associated with the slowing of relaxation of fatigued mouse muscle. J Physiol (Lond) 251:287-301

36. Maclennan DH, Zubrzycka-Gaarn E, Jorgensen AO 1985 Assembly of the sarcoplasmic reticulum during muscle development. Curr Top Membr Transp 24:337-368

37. Maxwell LC, McCarter RJM, Kuehl TJ, Robotham JL 1983 Development of histochemical and functional properties of baboon respiratory muscles. $J$ Appl Physiol 54:551-561

38. Viires N, Aubier M, Murciano D, Marty C, Pariente R 1986 Effects of theophylline on isolated diaphragmatic fibers. Am Rev Respir Dis 133:10601064

39. Davi M, Rigatto H 1985 Apnea. In: Nelson NM (ed) Current Therapy in Neonatal-Perinatal Medicine. CV Mosby, St. Louis, pp 147-149

40. Aranda JV, Grondin D, Sasyniuk BI 1981 Pharmacologic considerations in the therapy of neonatal apnea. Pediatr Clin N Am 28:113-133

41. Ogilvie RI, Fernandez PG, Winsberg F 1977 Cardiovascular response to increasing theophylline concentrations. Eur J Clin Pharmacol 12:409-414 